\title{
GIS Implementation in MNERGA Schema using Bhuvan Portal
}

\author{
Sadanand, Ravindra Prawasi, Ritesh Kumar, M.P. Sharma, Abhishek Sharma
}

\begin{abstract}
Government of India through MNREGA scheme is trying to fulfill the critical requirement of focused Panchayat asset mapping for the proper analysis of the required resources to be channelized for the overall wholesome development of the Panchayat in India. One such step taken by ISRO was to develop an Android Application for Panchayat Asset Mapping of the villages for generating database that will assist the government to study and channelize resources and funds for a proper controlled futuristic development of the Panchayat. The Panchayat Asset Mapping Application gives the citizens the privilege to contribute to this national project through a citizen login that can be easily registered through the Panchayat Asset Mapping Android Application.
\end{abstract}

Keywords- Asset mapping, Data collection, Upload Asset, Activity planning, View Asset.

\section{INTRODUCTION}

The Mahatma Gandhi NREGA GIS Solution intends to provide a single and integrated view of asset information system pan rural India. GIS enabled portal (e-Governance) will act as a gateway to facilitate and coordinate the exchange and sharing of geospatial data between stakeholders from various jurisdictional levels in the spatial data community

Asset Mapping: - asset mapping is the comprehensive compilation of different type of assets/resources available in different parts of the country which are created / being created under various schemes of government of india, states and communities by themselves to facilitate the local population.

Data Collection: - Collection of govt/pvt. Assets ground truth point, photographs, through mobile application (Bhuvan Panchayat 08 Nov 2014).Login in Mobile application and capture govt/pvt. Assets through the mobile application and send to Bhuvan portal of NRSC which can then be viewed on the same Points.

Point asset: - Power poles, Street, lights, Halogens,

Transformers.

Polygon asset: - Village ponds, water tanks.

Revised Manuscript Received on February 05, 2020.

* Correspondence Author

Sadanand*, Project Assistant, Haryana Space Applications Centre

Email: sadabhu@gmail.com

Ravindra Prawasi, Assistant Scientist (Urban Planning) at the Haryana Space Applications Centre.

Ritesh Kumar, Assistant Scientist (Forestry) at the Haryana Space Applications Centre.

M.P Sharma, Senior Scientist SG (Geoinformatics) at the Haryana Space Applications Centre.

(C) The Authors. Published by Blue Eyes Intelligence Engineering and Sciences Publication (BEIESP). This is an open access article under the CC BY-NC-ND license (http://creativecommons.org/licenses/by-nc-nd/4.0/)

\section{GIS IMPLEMENTATION IN MNERGA}

Under the 100 days employment guarantee scheme in MNERGA, Geographic Information system is planned to be implemented to capture assets present in villages. For mapping of assets, Bhuvan Panchayat asset mapping is being used in conjunction with the android application which needs to be installed on the android based mobile. This mobile application facilitates capturing of photographs with the geographical coordinates which further can be uploaded to the Bhuvan portal. Contents of the paper are fine and satisfactory. Author (s) can make rectification in the final paper but after the final submission to the journal, rectification is not possible.

\section{STUDY AREA}

Gangwa is a village Panchayat located in the Hisar district of Haryana State, India. The latitude $29^{\circ} 7^{\prime} 22^{\prime \prime} \mathrm{N}$. and longitude $75^{\circ} .41^{\prime} 57^{\prime \prime} \mathrm{E}$ are the geographic coordinate of the Gangwa. Chandigarh is the state capital of Haryana. It is located around 208.6 kilometers away from Gangwa Village Hisar. The country Capital Delhi is at distance of 154.4KM. Gangwa is in Administrative division of Hisar-1Block of Hisar district. The nearest railway station to Gangwa is Hisar which is located in and around 6.7 kilometer.

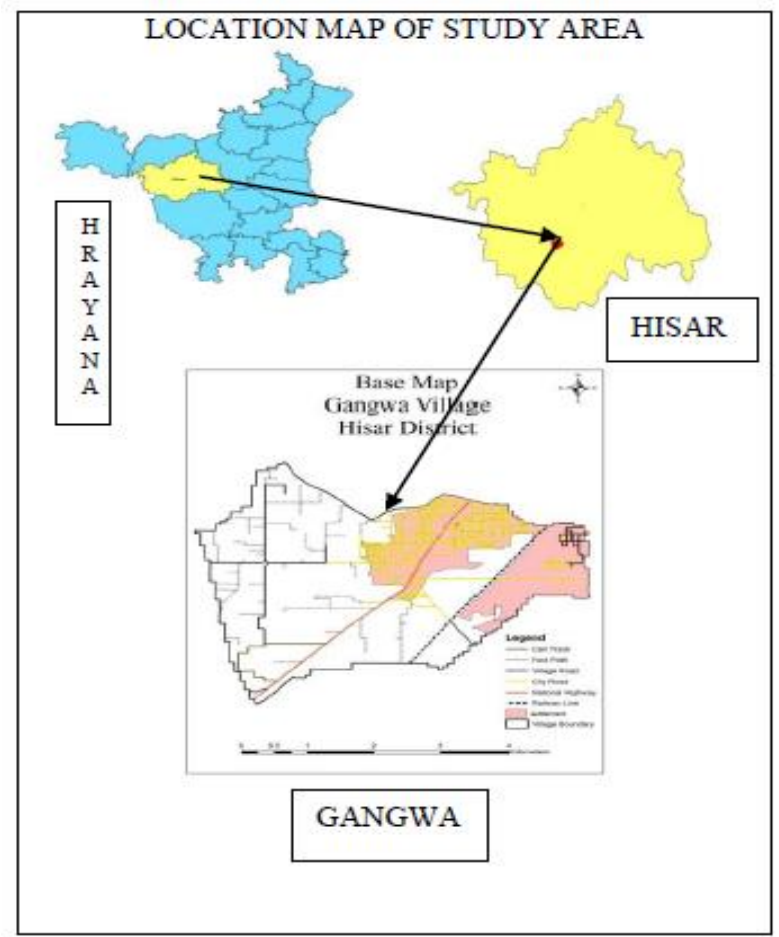

Fig: 1. Location map of study area 


\section{GIS Implementation in MNERGA Schema using Bhuvan Portal}

\section{MATERIALS AND METHODOLOGY}

Point Assets in the Power and Energy category whose coordinates and pictures have been collected are the following.

1.Power poles, Street lights, Halogens, Transformers

2. Polygon Assets: - Village ponds, water tanks.

Procedure of taking Polygon assets:

1. Click on polygon option

2. Click 'Add Vertex' to capture the vertices at the edge of the pond one after the other.

3. Click End line/poly on end of the polygon.

4. Click on 'Take Photo' to capture the asset picture.

After completion of the polygon feature, it is then uploaded on the Bhuvan Panchayat Application.

Gangwa Village pond appears in Bhuvan Panchayat portal.

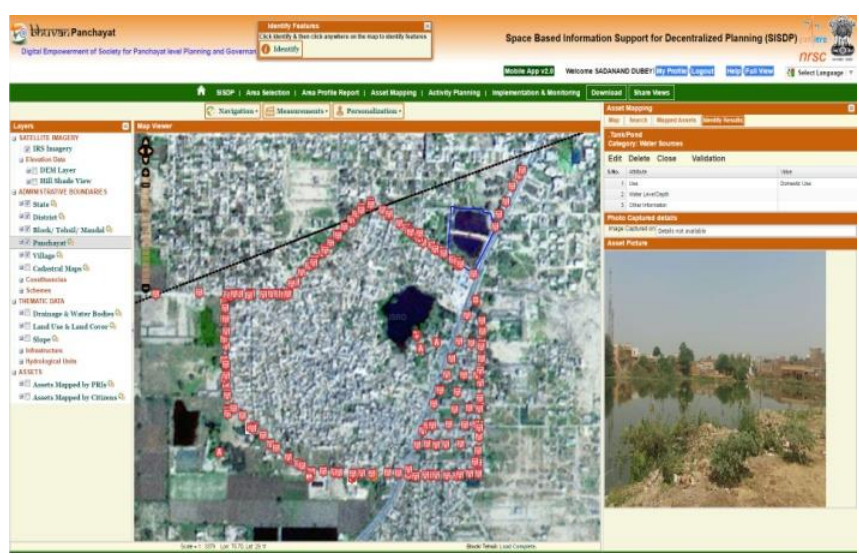

Fig:2 Pond Asset Boundary

\section{RESULTS AND DISCUSSIONS}

The study was carried out in the Gangwa village part of Hisar district. The study clearly established that the Bhuvan Panchayat Asset Mapping Android Application can be powerful tool for mapping and evolution of govt. /pvt assets mapping. Indian Government has turned on the scheme for the village. Under these schemes all of the 100-day em Scheme consists of development work. Asset (pond, school, electric pole) mapping task of Gangwa village was accomplished with this project.

\section{Different Scheme in Bhuvan Panchayat Asset mapping: -}

1. Mahatma Gandhi national rural employment guarantee scheme.

2. Integrated watershed management programme.

3. Pradhan mantri gram sadak yojana.

4. National rural drinking water mission.

5. Sarva siksha abhiayan.

6. National social assistance programme.

7. National health mission

\section{Activity Planning:}

Under activity planning I did suggest the following activities which are most required for the development of Village Gangwa.
- $\quad$ Activity Planning for MNERGA Act in Gangwa Village Pond should be done for around boundary Proposed Plan and Water Conservation.

Remote Sensing (RS) and Geographical information system (GIS) can be effectively used to collect, store and analyze assets (Watershed locations, Farm ponds, percolation tanks, check dams, road layer, Irrigation Channels etc.). With the use of GIS in the area of asset management, it is possible to visualize and understand the geographical context of an asset and improve the efficiency of asset management. The GIS enabled portal will maintain, process, store, and improve the

utilization of geospatial data for planners, decision makers and public.

\section{MNERGA SCHEMA IN GANGWA VILLAGE}

Assets created under MNERGA include agricultural facilities like manmade pond, Conservation and harvesting water for village such assets will be geo -tagged with picture and will be visible on the government owned Bhuvan mapping platform.

\section{Activity Planning: -}

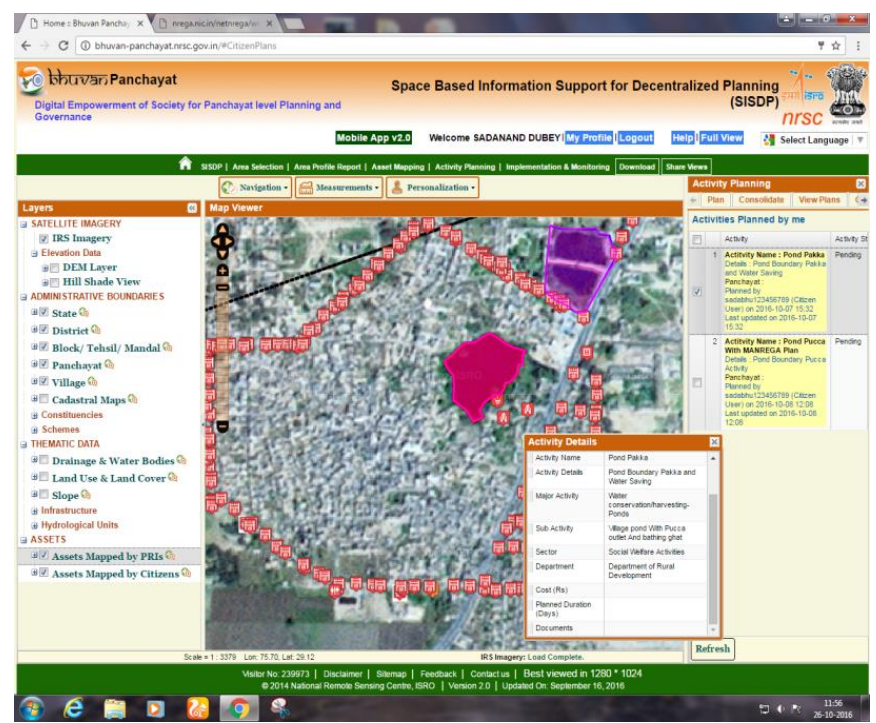

Fig:3. Activity Planning in Gangwa village (Hisar)

Gangwa village Proposed Plan for water Conservation and boundary wall. 


\section{Activity Plan Village pond Gangwa: -}

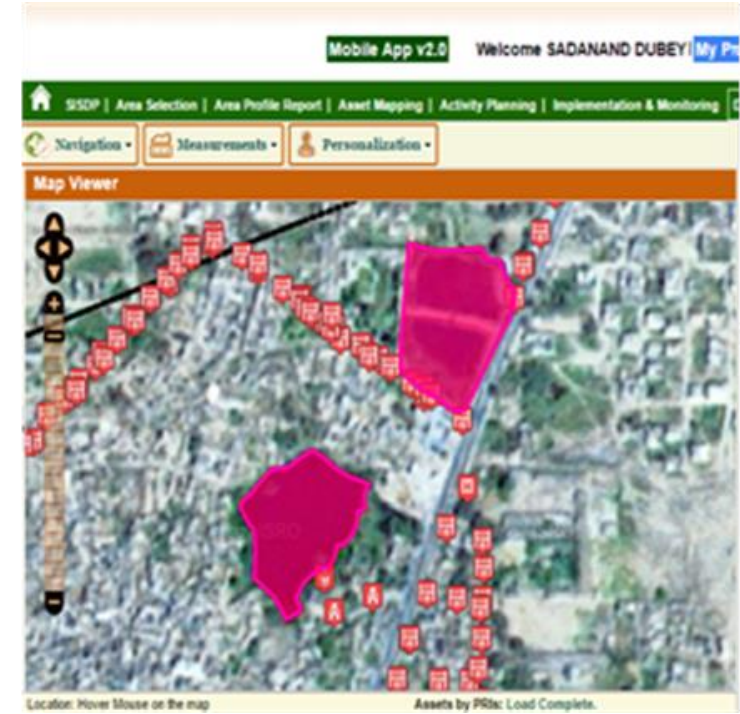

Fig:4. Electrical Assets and Pond boundary polygon

Under MNERGA we propose for the construction of cemented boundary of the ponds highlighted in red colour in the left-hand side image.

\section{CONCLUSION}

In the paper include the geographical information system join a very important role. It shows assets electricity system, pole and other important such as ponds, electric transformer, etc. in the village through the application of Bhuvan portal android mapping.

This portal can be easily seen by the office person, municipal corporation and village people through the Bhuvan android application after logins, this work especially inspired by Mahatma Gandhi national rural employment guarantee act. The main advantage of asset Mapping of electric poles, transformers all important requirement i.e. complaint easily send by application, and any other proposal for development like watershed, school and other very easy by portal. This study is also very helpful to improvement, requirements, and complaints other important future activity.

\section{REFERENCES}

1. Space Based Information Support for Decentralized Planning (SIS-DP), Nagaraja Ravoori, Project Director, SIS-DP.

2. Mobile Based Asset Mapping for Panchayat /Equivalent Bodies on GIS Platform, Bhuvan Panchayat Mobile Application, NRSC.

3. Mahatma Gandhi National Rural Employment Guarantee Act (MNERGA), Ministry of Rural Development Manual.

4. Integrated Water Management Program (IWMP)

5. Bhuvan Panchayat Manual NRSC Hyderabad.

6. NIRD, Bhuvan App Pdf.

7. Rai P. K. and C. Singh. GIS in Electrical asset Mapping the Case of Bhadohi, India. European Journal of Geography-ISSN 1792-1341

\section{AUTHORS PROFILE}

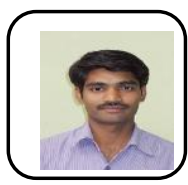

Sadanand received the MA (Geography) From Naland Open University, Patna and M. Tech Geoinformatics from Guru Jambheswar University of Science \& Technology, Hisar. Project assistant at Haryana Space Applications Centre, Hisar, Department of Science and Technology Haryana.
Activity 1 - UnderMNERGA we propose for the construction of cemented boundary of the ponds highlighted in red colour in the lefthand side image.

Activity 2 - We propose the development of the above-mentioned ponds firstly for rain waterharvesting as well as for purposes of the village of

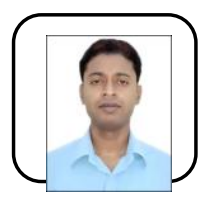

Ritesh Kumar Assistant Scientist (Forestry) at Haryana Space Applications Centre, Hisar Department of Science and Technology Haryana.

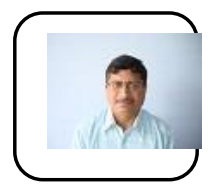

M.P. Sharma Senior Scientist SG (Geoinformatics) a Haryana Space Applications Centre, Hisar Department of Science and Technology Haryana.

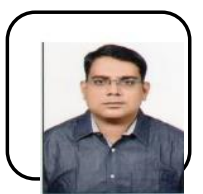

Abhishek Sharma received the MA (geography) from MDS University, Ajmer and M.Tech Geoinformatics from Guru Jambheswar University of Science \& Technology, Hisar. 